\title{
Featuring the Demand Met by Senior Medical Students in Primary Health Care Units in Southern Brazil
}

\author{
Gilmor José Farenzena1, Leris Salete Bonfanti Haeffner², \\ Angela Regina Maciel Weinmann' ${ }^{3}$, Bruna Biazi ${ }^{4}$, Alexandre Kieslich da Silva ${ }^{5}$, \\ Maria Rosa Chitolina Schetinger ${ }^{6}$ \\ ${ }^{1}$ Community Health Department at Federal University of Santa Maria, Santa Maria, Brazil \\ ${ }^{2}$ Faculty of Medicine of the Franciscan University Center, Santa Maria, Brazil \\ ${ }^{3}$ Pediatric Department at Federal University of Santa Maria, Santa Maria, Brazil \\ ${ }^{4}$ Faculty of Medicine, Federal University of Santa Maria, Santa Maria, Brazil \\ ${ }^{5}$ São Pedro Hospital, Porto Alegre, Brazil \\ ${ }^{6}$ Biochemistry and Molecular Biology Department at Federal University of Santa Maria, Santa Maria, Brazil \\ Email: gilmorf@gmail.com, franciscano-leris.haefner@gmail.com,noca@rocketmail.com, \\ brunahbiazi@gmail.com, akieslich@gmail.com,mariachitolina@gmail.com
}

Received 19 June 2016; accepted 18 July 2016; published 21 July 2016

Copyright (C) 2016 by authors and Scientific Research Publishing Inc.

This work is licensed under the Creative Commons Attribution International License (CC BY).

http://creativecommons.org/licenses/by/4.0/

(c) (i) Open Access

\section{Abstract}

Featuring the demand in Primary Health Care (PHC) units is essential to properly perform healthrelated diagnosis. In addition, it is an important pedagogical tool used to teach about the real population health needs. This is a cross-sectional study-with random sample-about the care provided by medical students in Southern Brazil, during their Mandatory Internship (MI) period. There was predominance of care given to female patients; $70 \%$ were adult or elderly individuals. The Systemic Arterial Hypertension (SAH) was the most diagnosed disease and it was followed by Upper Airway Diseases and by Musculoskeletal Pain. Laboratory tests were requested in less than $20 \%$ of the cases and imaging tests were requested in less than $7 \%$ of them. The patients were referred to other health care levels in $25 \%$ of the cases. The current study helped featuring the epidemiological profile of users in Primary Health Care (PHC) units wherein medical residents of the Federal University of Santa Maria (UFSM-Universidade Federal de Santa Maria) realized their final course activities. Thus, the results of such featuring may help redirecting the didactic and pedagogical activities, which are required to enable a medical training focused on the population health needs. 


\section{Keywords}

\section{Demand Featuring, Medical Education, Primary Health Care}

\section{Introduction}

The medical education model, which is centered on the individual and curative care and shows hospital-centered features that depend on the incorporation of hard technologies, has changed in Brazil, in recent decades (Batista et al., 2015; Brazil, 2001; Brazil, 2014). The aim of these changes is to provide a medical training in line with the real health demands and needs of populations (Feurerwerker, 2002) and to allow a true paradigm shift in medical education (Kuhn, 1990; Lampert, 2002). This is one of the main concerns of the National Curriculum Guidelines for Undergraduate courses in Medicine. The guidelines were issued by the Brazilian Federal Board of Education in 2001 and updated in 2014 (Brazil, 2001; Brazil, 2014). The UFSM-RS Medical School changed its curriculum in 2004 in order to adapt it to such guidelines (Ministry of Education, 2004). The PHC internship was established at that occasion as a way to provide the students with a rich and innovative experience that goes "beyond the walls" of the UFSM and of the University Hospital (Brazil, 2014; Ministry of Education, 2004). Such training format allows graduate students to perform PHC-related activities in Primary Health Care units of some counties located in the Midwestern Macroregion of Rio Grande do Sul State (Ministry of Education, 2004). The activities are performed under the direct guidance of medical preceptors from municipal health networks and supervised by UFSM Medical School professors. The PHC is characterized by a set of individual and collective health interventions, which comprise health promotion, as well as the prevention, diagnosis and treatment of certain health issues that prevail among the population (Souza Campos, 2007). These health issues are usually little complex and may be treated through light (comprise the production of communication and relations) and light-hard technologies (comprise structured knowledge) (Merhy, 2005). The PHC activities should be able to solve $85 \%$ of the health issues, as well as to coordinate flows and counter flows and to take responsibility for the health of ascribed populations (Batista et al., 2015; Brazil, 2014; World Health Organization, 2003). Ideally, they work through the integration of individual and collective actions, as well as of curative, preventive, social and educational ones (Batista et al., 2015; World Health Organization, 2003). The treatment needs in PHC units are many and they vary according to the unit's location, but most clinical consultations are restricted to few diagnoses (Batista et al., 2015; Streit et al., 2009; Beaglehole et al., 2008; Starfield, 2002).

Specific regional factors such as climate and demographic profile should be also taken into consideration in continental countries such as Brazil (Almeida-Filho, 2015). The proper management of the 30 most frequent diagnoses may have a positive impact on the health status of these populations (Duncan et al., 2013). Thus, featuring, assessing and monitoring the performance of such services is important and necessary in order to support proposals that seek to improve health care quality (Batista et al., 2015; Streit et al., 2009; Souza Campos, 2007; Costa, 1997; Radaeli et al., 1990). Therefore, it is worth including undergraduate students in such activities as a way to provide them with proper professional training (Duncan et al., 2013; Pimentel et al., 2011; Smith, 2013).

Similar activity models were experimented by other national and international Medical Schools and showed significant results (Federal University of Minas Gerais, 2009; Ruiz et al., 1985; Santa-Rosa et al., 2007). The University of Illinois developed a medical education program in rural areas and found that the undergraduate students who experienced it were 14.4 times more prone to choose family medicine and 6.7 times more prone to choose a primary medical specialty. In addition, they were 17.2 and 12.8 times more prone to work in rural areas and in primary health care units, respectively, than those who did not experience it (Macdowell et al., 2013). The Rural Internship at the Federal University of Minas Gerais (Federal University of Minas Gerais, 2009) which was developed in the institution over 30 years ago, and the Regional Internship of the UFSM Medical School, which was launched in 2006 (Ministry of Education, 2004; Ruiz et al., 2010) are other models of such potentially transformative activities. According to Ruiz et al. (2010), the PHC internship had positive impact on the self-confidence to exercise Medicine in $86 \%$ of the medical interns in Southern Brazil.

The current study is justified by the need of reliably featuring the health demand in PHC services in Southern Brazil, during the MI of UFSM Medical School students. 


\section{Population and Methods}

The current study, which adopted a cross-sectional design, assessed 1673 clinical consultations conducted by Medical School students in Primary Health Care units located in some counties of the Midwestern Macroregionin Rio Grande do SulState (Agudo, Alegrete, Faxinal do Soturno, Formigueiro, Jari, Restinga Seca, Santa Maria, São Gabriel and Uruguaiana), from April to July 2013. The main advantage of this type of study lies on the fact that it has attributes that allow describing the features of a certain population based on a representative sample of it. In addition, it may be conducted within a short period of time and at a relatively low cost. It also allows analyzing the possible associations between the studied risk factors, as long as such analysis is subjected to a pre-established model (Pereira, 2009; Piccini \& Victora, 1994). The current study is part of the project called "Primary Health Care: The Regional Internship in the UFSM Medicine Undergraduation Course", approved at UFSM, and developed in partnership with the Municipal Health Department of the ascribed counties (Ministry of Education, 2004).

Sixth-year medical students were randomly distributed in the ascribed counties of the Midwestern Macroregion of Rio Grande do Sul State. They remained in these counties for four months in order to accomplish the mandatory internship in Primary Health Care. The clinical consultations were held under the guidance of the physician (preceptor) in charge of the unit and supervised by UFSM Medical School professors (Ministry of Education, 2004).

The exclusion criterion comprised the services directly provided by the preceptor physician, without the student's participation. Seventy-eight (4.3\%) out of the 1,805 clinical consultations held by the medical students were disregarded due to poorly defined diagnosis and 54 (3.0\%), due to lack of diagnosis. Thus, the sample of the current study comprised 1673 clinical consultations. The patients' identity was preserved and a number was assigned to each of them in the data analysis.

The protocol filled in by the medical students provided the herein studied variables, namely: age, gender, main reason for the clinical consultation, need and type of additional tests requested, and referral to specialized services. No classification system, such as the International Classification of Diseases (ICD) or the Clinical Information Access Portal (CIAP), was used. The classification was defined in the study itself.

The "age" variable was distributed into eight categories established as follows: younger than 1 year, from 1 to 4.9 years old, from 5 to 9.9 years old, from 10 to 19.9 years old, from 20 to 39.9 years old, from 40 to 59.9 years old, from 60 to 79.9 years old, and 80 years old or older. The additional test types were classified as laboratory test, radiography, ultrasonography, and computed tomography/magnetic resonance imaging. The main reasons for the clinical consultation were set by the medical students under the preceptor physician's supervision. The data were inserted in an Excel spreadsheet and analyzed through the STATA 10 software. Frequency tables were developed and the test between two ratios was used to check the difference between genders, according to age group. The difference presenting $p<0.05$ was considered significant. The current study was approved by the Research Ethics Committee of UFSM, under the Opinion N 260024300010. There is no conflict of interest in the current study.

\section{Results}

The analysis encompassed 1673 clinical consultations held in primary health care units, $61.4 \%$ with female patients and $38.6 \%$ with male patients $(p=0.001)$. The clinical consultations with male patients were prevalent among children younger than one year and among those in the age group between 5 and 10 years old. The percentage of clinical consultations with female patients was higher in other age groups $(p=0.001)$. The largest number of clinical consultations was held with patients in the age group between 40 and 60 years old (31.8\% of the clinical consultations), and it was followed by the age group between 20 and 40 years old (21.3\%) and by that between 60 and 80 years old (20.9\%). Thus, $70.0 \%$ of the clinical consultations were held with adult or elderly patients (Table 1 ).

One hundred and twenty-six (126) different reasons for clinical consultation were observed in the current study. Table 2 presents the 10 most observed ones. The SAH was the main reason for treatment in $12.5 \%$ of the clinical consultations, and it was followed by Upper Airway Diseases (12.0\%) and by Musculoskeletal Pain (8.0\%). 
Table 1. Distribution of health care services conducted by Medical School students in Primary Health Care units, according to age and gender.

\begin{tabular}{|c|c|c|c|c|c|c|}
\hline \multirow{3}{*}{ Age Group } & \multirow{3}{*}{ NT (\%) } & \multicolumn{4}{|c|}{ Gender } & \multirow{3}{*}{$P^{*}$} \\
\hline & & \multicolumn{2}{|c|}{ Male } & \multicolumn{2}{|c|}{ Female } & \\
\hline & & $\mathbf{N}$ & $\%$ & $\mathbf{N}$ & $\%$ & \\
\hline$<1$ & $34(2.0)$ & 22 & 64.7 & 12 & 35.3 & 0.001 \\
\hline $1-4.9$ & $91(5.4)$ & 43 & 47.3 & 48 & 52.7 & 0.209 \\
\hline $5-9.9$ & 111(5.9) & 66 & 59.5 & 45 & 40.5 & 0.001 \\
\hline $10-19.9$ & 132 (7.9) & 47 & 35.6 & 85 & 64.4 & 0.001 \\
\hline $20-39.9$ & 357 (21.3) & 110 & 30.8 & 247 & 69.2 & 0.001 \\
\hline $40-59.9$ & 532 (31.8) & 184 & 34.6 & 348 & 65.4 & 0.001 \\
\hline $60-79.9$ & 349 (20.9) & 143 & 41.0 & 206 & 59.0 & 0.001 \\
\hline$\geq 80$ & $67(4.0)$ & 31 & 46.3 & 36 & 53.7 & 0.177 \\
\hline TOTAL & $1673(100)$ & 646 & 38.6 & 1027 & 61.4 & 0.001 \\
\hline
\end{tabular}

NT = total frequency; $\mathrm{N}$ = frequency; \% = percentage; *Test between two ratios.

Table 2. Distribution of reasons for seeking health care services provided by Medical School students in Primary Health Care units.

\begin{tabular}{cccc}
\hline Clinical Diagnosis & N & \% \\
\hline 1. $\quad$ Total number of clinical consultations & 1673 & 100.0 \\
Systemic Arterial Hypertension & 209 & 12.5 \\
$\quad$ Upper Airway Diseases & 200 & 12.0 \\
Musculoskeletal Pain & 134 & 8.0 \\
Injuries & 53 & 4.0 \\
Diabetes Mellitus & 83 & 3.7 \\
Depression & 77 & 3.4 \\
Urinary Tract Infection & 61 & 3.1 \\
Conjunctivitis & 57 & 3.0 \\
Gastroenteritis & 51 & 50 & 2.0 \\
\hline
\end{tabular}

$\mathrm{N}=$ Frequency; \% = percentage of diagnosis relative to the total number of clinical consultations.

Table 3 shows the frequency of requests for additional tests. Laboratory tests were required in $18.2 \%$ of the assessed clinical consultations. The most requested tests were blood count, qualitative urine test, as well as plasma urea and creatinine concentrations. As for the imaging examinations, radiography was requested in $4.9 \%$ of the clinical consultations, and it was followed by ultrasonography (2.8\%) and by computed tomography or magnetic resonance imaging $(0.2 \%)$.

The need of referring the patients to specialized medical services or to other health professionals is shown in Table 4. One hundred and forty-seven (147) out of the 1673 patients were referred, and it represented 8.8\% of the clinical consultations. Among these 147 patients, 20.4\% were referred to the UFMS University Hospital and the others (79.6\%) were referred to local or regional specialized services.

Table 5 shows the distribution of the three main reasons for clinical consultation, according to age group. It is possible noticing that the upper airway infection prevailed in the first five analyzed age groups, i.e., from the age 
Table 3. Distribution of additional tests requested for the patients who were taken care of by Medical School students in the Primary Health Care units.

\begin{tabular}{|c|c|c|}
\hline Additional Tests & $\mathbf{N}$ & $\%$ \\
\hline Total number of clinical consultations & 1673 & 100.0 \\
\hline Laboratory Tests & 305 & 18.2 \\
\hline Radiography & 82 & 4.9 \\
\hline Ultrasonography & 47 & 2.8 \\
\hline CT scan/MRI & 3 & 0.2 \\
\hline Total requested tests & 437 & 26.1 \\
\hline
\end{tabular}

$\mathrm{N}=$ frequency; $\%$ = percentage of requested tests relative to the total number of clinical consultations; $\mathrm{CT}$ scan/MRI = Computed Tomography/Magnetic Resonance Imaging.

Table 4. Distribution of referrals required for the patients who were taken care of by Medical School students in the Primary Health Care units.

\begin{tabular}{ccc}
\hline Certified Specialized Services & N & \% \\
\hline $\begin{array}{c}\text { Specialized services of the HUSM } \\
\text { Specialized services of the county or region } \\
\text { Nutrition }\end{array}$ & 30 & 20.4 \\
General Surgery & 21 & 14.3 \\
Psychology & 15 & 10.2 \\
Ophthalmology & 14 & 9.5 \\
Gynecology & 14 & 9.5 \\
Otorhinolaryngology & 13 & 8.8 \\
Physiotherapy & 12 & 8.2 \\
Nephrology & 11 & 7.5 \\
Cardiology & 9 & 6.2 \\
Total number of referrals & 8 & $\mathbf{1 4}$ \\
\hline
\end{tabular}

$\mathrm{N}=$ frequency; $\%$ = percentage of referrals relative to the total number of clinical consultations.

Table 5. Distribution of the three main reasons for health care taking, set by Medical School students in the Primary Health Care unit, according to age group.

\begin{tabular}{|c|c|c|c|}
\hline Main Reasons According to Age Group & NT & $\mathbf{N}$ & $\%$ \\
\hline Younger than one year & 34 & & \\
\hline Upper Airway Diseases & & 11 & 32.4 \\
\hline Childcare & & 10 & 29.4 \\
\hline LowerAirway Diseases & & 4 & 11.6 \\
\hline From 1 to 4 years old & 91 & & \\
\hline Upper Airway Diseases & & 34 & 37.4 \\
\hline Worm Infection & & 6 & 6.6 \\
\hline Anemia & & 5 & 5.5 \\
\hline
\end{tabular}




\section{Continued}

From 5 to 9 years old

Injuries

Gastroenteritis

Upper Airway Diseases

From 10 to 20 years old

Upper Airway Diseases

Injuries

Prenatal

From 20 to 39 years old

Upper Airway Diseases

Musculoskeletal Pain

Injuries

From 40 to 59 years old

Systemic Arterial Hypertension

Musculoskeletal Pain

Depression

From 60 to 79 years old

Systemic Arterial Hypertension

Musculoskeletal Pain

Diabetes Mellitus

$\geq 80$ years old

Depression

Systemic Arterial Hypertension

Cerumen Impaction

111

$\begin{array}{ll}53 & 47.8 \\ 8 & 7.2 \\ 6 & 5.4\end{array}$

132

15

11.5

6.9

357

37

10.4

36

10.1

27

7.6

532

$\begin{array}{ll}87 & 16.4 \\ 62 & 11.7 \\ 27 & 5.1\end{array}$

349

$\begin{array}{ll}73 & 20.9 \\ 32 & 9.2 \\ 18 & 5.2\end{array}$

67

$\begin{array}{ll}8 & 11.9 \\ 6 & 9.0 \\ 6 & 9.0\end{array}$

$\mathrm{NT}$ = total frequency of clinical consultations according to age group; $\mathrm{N}=$ frequency; $\%$ = percentage of diagnosis relative to the total number of clinical consultations in the age group.

group younger than one year to that of incomplete 40 years. The SAH was the most frequent disease among patients aged between 40 years and incomplete 80 years. Depression was the most common reason (11.9\%) for clinical consultations in patients aged 80 years or older. It was followed by SAH and Cerumen Impaction, which were found in $9.0 \%$ of the patients.

\section{Discussion}

The current study was based on data systematically collected by medical students during their mandatory internship activities, which were carried out in PHC units, throughout their last year in Medical School (Ministry of Education, 2004; Brazil, 2014). The information concerns the population treated in the Primary Health Care units, the need of complementary tests, and the referrals to specialized centers.

With respect to gender, it was possible observing the predominance of female patients in over $60 \%$ of the assessed clinical consultations. According to the literature, the female patients' demands are higher than those of the male ones. In addition, the search for health care is essentially voluntary, which reveals the greater propensity of women to spontaneously seek it (Batista et al., 2015; Pimentel et al., 2011). Data from the 2010 Brazilian 
census conducted by IBGE show the predominance of women with higher life expectancy in the population (IBGE, 2016). Abundant evidences demonstrate the predominance of care given to women in health services (Batista et al., 2015; Pimentel et al., 2011; Pereira, 2009; Barret, 1996; Faleiros et al., 1986). The less formal inclusion of women in the labor market, their greater availability of time, and their different perception about the health-disease process appear to play an important role in such predominance (Faleiros et al., 1986). The results are similar in both outpatient services and more complex hospital services (Sala et al., 1998; Faleiros et al., 1986). On the other hand, the male patients' demands are mostly linked to both labor and social security needs, rather than to the specific need of treating or preventing diseases (Landsberg et al., 2012; Sala et al., 1998; Barret, 1996; Faleiros et al., 1985).

Patients in the age group between 40 and 59.9 years were the most treated by medical students in the health care services where these students performed their activities. By assessing the patients' profile according to age group, it was observed that more than half of the patients were older than 40 years, a third of them were between 40 and 59.9 years old, and a fifth of them were between 60 to 79.9 years old. A cross-sectional study conducted by Azeredo et al. (2007) found 36\% of patients in the age group between 40 and 59.9 years, whereas Magnago et al. (2009) found 33\% at the same age group, in Santa Catarina State. Similar studies conducted in Pelotas County-RS found from $55 \%$ to $70 \%$ demand between middle-aged and early-elderly patients, which meets the onset of chronic diseases, as well as the ability to autonomously seek medical care (Moraes et al., 2007; Capilheira \& Santos, 2006). Tomasi et al. (2011) compared the profile of the demand met in the Primary Health Care units of seven Brazilian states in the Southern and Northeastern regions and found that the demand was distributed as follows: $24 \%$ children, $37 \%$ women and $37 \%$ elderly. The same profile was found in other studies, and it showed that each health care service must know its demand profile (Tomasi et al., 2011; Capilheira \& Santos, 2006; Golbaum et al., 2005; Mendoza-Sassi \& Béria, 2001). Such information concerning the age group is of great importance since it allows sizing the workload in primary health care services. It can be assumed that the increased demand for care at the age group between 40 and 59.9 years old is related to the high incidence of chronic diseases in this age group (Tomasi et al., 2011; Capilheira \& Santos, 2006). The increased life expectancy of the population in Rio Grande do Sul State in the last decades also contributes to these findings (IBGE, 2016).

Systemic arterial hypertension was the most prevalent reason for seeking medical care- $12.5 \%$ of the total cases. According to the literature, SAH is the leading cause of outpatient consultation in primary health care units (Landsberg et al., 2012; Travassos et al., 2002; Brazil, 2006; Faleiros et al., 1986). The disease has impact on health indicators and it is also related to disability and early retirement (Brazil, 2014; Pimentel et al., 2011; Magnago et al., 2009; Goldbaum et al., 2005). On the other hand, it is possible seeing the allocation of important public resources aiming at the hospitalization and rehabilitation of hypertensive individuals, since many of them are affected by the disease during their productive life (Brazil, 2014; Brazil, 1997; Ruiz et al., 1985). According to the Brazilian Ministry of Health, SAH is a major cardiovascular disease, which has significantly increased in recent years, thus affecting 20 million Brazilian citizens (Brazil, 2014). In addition, estimates show that there are 3 undiagnosed or late diagnosed hypertensive patients for each diagnosed person in Brazil (Brazil, 2014; Brazil, 2007; Brazil, 1997).

The Upper Airway Diseases were the second major reason for seeking treatment in the current study, and they are the leading cause of health treatment in patients aged up to 20 years. Thus, the period of the year covered by the current study should be taken into account, since it comprised fall and winter months. In addition, the geographic location of Rio Grande do Sul State is characterized as a sub-tropical climate region (IBGE, 2016), which presents cold and varying weather and extreme temperatures. These fluctuations lead to seasonal increase in the demand for health care to treat these diseases in this Brazilian State (IBGE, 2016). The cold weather, with rain or increased barometric pressure, leads to increased respiratory distress in susceptible patients and favors the reactivation of medical conditions such as asthma or allergic rhinitis, as well as the increased transmission of infectious and contagious diseases (Rondet et al., 2010).

Musculoskeletal Pain was the third reason for seeking health care and it was also found in studies conducted by other authors (Magnago et al., 2009). Nowadays, it is one of the most common complaints and one of the main reasons for seeking PHC services (Magnago et al., 2009). Painful manifestations of this nature may reach epidemic levels. They may lead to relevant personal, epidemiological and social consequences, and they may also have a strong impact on health care services (Magnago et al., 2009). Estimates made by several authors showed that $70 \%-90 \%$ of the population presented such type of pain at some point in their lives (Magnago et 
al., 2009). Given their importance, painful manifestations require the proper training of the professionals who will work in health care services.

Thus, allowing Medical students to feature the demand profile in health care units exposes these young apprentices to the reality they will face in their future professional lives (Beaglehole et al., 2008). The experiences that help identifying these conditions and that provide the proper training to solve them have a transformative potential in the proper treatment of health issues (Magnago et al., 2009). On the other hand, they are an important didactic and pedagogical element in the orientation of a medical education more committed to the health, epidemiological and social realities (Batista et al., 2015; Duncan et al., 2013; Ruiz et al., 2010).

The additional tests are important elements used to confirm diagnoses. They arealso important tools used to guide the clinical reasoning in other clinical situations, especially when the quantity or the quality of information is poor or when the anamnesis and the physical examination are inconsistent (Batista et al., 2015; Magnago et al., 2009; Pereira, 2009). As for the PHC activities carried out in Primary Health Care units, it is expected that the medical professional needs to request some type of additional test to help $t$ he diagnosis in approximately $10 \%$ of the clinical consultations (Ottmani et al., 2004; Sala et al., 1998). On the other hand, according to the guidelines of the Brazilian Ministry of Health, between 30 and 50 laboratory tests, 5 and 8 radiological examinations, 1 and 1.5 Ultrasonography tests, and 0.01 and 0.04 Computed tomography or MRI can be requested for every 100 clinical consultations (Brazil, 2002). The current study found that at least one type of additional test was requested in $25 \%$ of the clinical consultations. As it can be seen, the requests for additional laboratory tests and RX showed levels below the limit established in the Ministry of Health guidelines. These data can mean that greater attention was given to the medical history and that the medical students have performed a thorough physical examination in the patients. According to such perspective, there would be the development of better diagnostic hypotheses and, consequently, the establishment of a more effective therapy with consequent increase in the case-resolving capacity of the care provided to the patients. Only the request for imaging tests, such as ultrasonography and CT/MRI, exceeded the limit set by the Ministry of Health. Part of the clinical consultations were held in inland counties of Rio Grande do Sul State, where such services are not usually available. Thus, it may explain such results.

Regarding the referrals to other reference centers, the PHC service showed great capacity to treat most of the health issues presented by the ascribed populations. The case-resolving capacity was found in $92 \%$ of the clinical consultations conducted by Medical students, under supervision. The evidences show that the PHC service is able to respond to $85 \%$ of the health demands through preventive, curative, rehabilitative and health promotion services (Batista et al., 2015; Duncan et al., 2013; Pimentel et al., 2011). Similarly, it is able to provide integrated health care in co-morbidity cases by dealing with the patients' concrete life context in their social habitat (IBGE, 2016; Starfield, 1994).

These results reinforce the importance of PHC activities for a medical training focused on the epidemiological and social conditions of the population. The proper use of the health system gateway services helps reducing the use of specialized secondary and tertiary level services. In addition, activities aimed at preventing diseases, which typically develop therein, may corroborate such reduction (Batista et al., 2015; Duncan et al., 2013; Merhy, 2005; World Health Organization, 2003; Starfield, 2002). On the other hand, this practice space in the reality of services showed that these students are able to make adequate diagnostic decisions, which will effectively help their professional performance in the future. Such considerations should enable the UFSM Medical School to reflect on the need of increasing the load of medical training activities in other professional practice environments, especially in PHC units.

\section{Conclusions}

The current study helped properly featuring the epidemiological profile of primary health care service users treated in the health care units where medical students carried out their activities, during their final training period.

The prevalence of women among the treated users was higher than that of men, and the predominant age group was above 40 years old. Such fact may reflect the greater need of health care in this age group, as well as the presence of chronic diseases with greater debilitating potential at this stage of life.

Diseases such as SAH, Upper Airway Diseases and Musculoskeletal Pain showed higher prevalence than others. The herein found clinical conditions were resolved through the request for additional tests, whose percentage was below the commonly accepted one. 
As for the referrals, the Primary Health Care showed to be clearly able to properly treat most of the diagnosed health issues, without making unnecessary referrals to specialized services.

In light of the foregoing, it is possible concluding that the featuring of the demand met by medical students performing MI in PHC units may be an important element in their final training. Thus, it could provide the tools for the future medical professionals to develop the necessary clinical skills in order to fulfill the real health needs of populations under their responsibility, throughout their professional lives.

\section{Conflicts of Interest}

The authors declare no conflicts of interest in the current study.

\section{References}

Almeida-Filho, N. de. (2011). Higher Education and Health Care in Brazil. The Lancet-Health in Brazil, London. http://www.abc.org.br/IMG/pdf/doc-574.pdf

Azeredo, C. M., Cotta, R. M., Schott, M., Maia, T. M., \& Marques, E. S. (2007). Assessment of Sanitation and Housing Conditions: The Importance of Home Visits in the Family Health Program Context. Ciência \& Saúde Coletiva, 12, 743753. http://dx.doi.org/10.1590/S1413-81232007000300025.

Barret, E. J. (1996). Primary Care for Women: Assessment and Management of Headache. Nurse Midwifery, 41, 117-124. http://dx.doi.org/10.1016/0091-2182(96)00002-X

Batista, N. A., Vilela, R. Q. B., \& Batista, S. H. S. S. (2015) Medical Education in Brazil (1st ed). São Paulo: Cortez Editora.

Beaglehole, R., Epping-Jordan, J., Patel, V., Chopra, M., Ebrahim, S., Kidd, M. et al. (2008). Improving the Prevention and Management of Chronic Disease in Low-Income and Middle-Income Countries: A Priority for Primary Health Care. Lancet, 372, 940-949. http://dx.doi.org/10.1016/S0140-6736(08)61404-X

Brazil, Labor Management and Health Education Secretariat. Health Education Management Department (2014). Learning; The NHS and the Undergraduate Courses in the Health Field. Brasília: Ministry of Health.

Brazil. Ministry of Education. National Board of Education. Higher Education Chamber (2001). Resolution CNE/CES No. 4, November 7th 2001. It Establishes the National Curriculum Guidelines for Undergraduate Studies in Medicine. Federal Official Gazette. Brasília, November $9^{\text {th }}$ 2001; Section 1, p. 38.

Brazil. Ministry of Health (1997). Protocol for Arterial Hypertension and Diabetes Mellitus. Reports in Public Health. Brasília: Ministry of Health.

Brazil. Ministry of Health (2002). Ordinance No. 1101/GM from June $12^{\text {th }} 2002$. http://saude.gov.br/sas/PORTARIA/Port2002/Gm/GM-1101.htm

Brazil. Ministry of Health. Secretariat of Health Care. Department of Primary Care (2006). Systemic Arterial Hypertension in the Unified Health System. Brasília: Ministry of Health.

Brazil. Ministry of Health. Secretariat of Health Care. Department of Primary Care (2014). Systemic Arterial Hypertension in the Unified Health System. Brasília: Ministry of Health.

Brazil. National Board of Education. Higher Education Chamber (2014). Resolution No. 3 from June 20th 2014. It Establishes the National Curriculum Guidelines for Medical School and other measures. Federal Official Gazette, Brasilia, DF, June 23rd 2014.

Capilheira, M. F., \& Santos, I. S. (2006). Individual Factors Associated with Medical Consultation by Adults. Revista de Saúde Pública [online], 40, 436-443. http://dx.doi.org/10.1590/S0034-89102006000300011

Costa, J. S.D. (1997). Use of Outpatient Services in an Urban Area of Southern Brazil: Place and Frequency. Revista de Saúde Pública, 31, 360-369.

Duncan, B. B., Schmidt, M. I., \& Giugliani, E. R. J. (2013). Ambulatorial Medicine: Clinical Behavior in Primary Care (4th ed.). Porto Alegre: Artes Médicas.

Faleiros, J. J., Martinez, J. C., Piccini, R. X., Adures, T. R. M. L., Neto, J. I. S. M., \& Silva, D. B. (1985). Most Frequent Reasons for Consultation and Use of a Primary Health Care Service. Revista da Associacao Medica do Rio Grande do Sul, 29, 297-300.

Faleiros, J. J., Piccini, R. X., Gigante, A. G., \& Neutzling, M. B. (1986). Practicing and Teaching Medicine in the Community: The Medical Care. Brazilian Journal of Medical Education, 10, 98-104.

Federal University of Minas Gerais (2009). Medical School. Rural Internship. Belo Horizonte: UFMG; c2000-2009 http://biblioteca.versila.com/?q=internato+rural

Feurerwerker, L. (2002). Beyond the Discourse of Change in Medical Education: Processes and Results. São Paulo: Hucitec. 
Goldbaum, M., Gianini, R. J., Novaes, H. M. D., \& César, C. L. G. (2005). Health Services Utilization in Areas Covered by the Family Health Program (Qualis) in São Paulo City, Brazil. Revista de Saúde Pública, 39, 90-99. http://dx.doi.org/10.1590/S0034-89102005000100012

IBGE (2016). Brazilian Institute of Geography and Statistics. Accessed on 04/30 http://www.censo2010.ibge.gov.br/sinopse/index.php?dados $=11 \& u f=00$

Kuhn, T. S. (1990). The Structure of Scientific Revolutions (3rd ed.). São Paulo: Perspectiva.

Lampert, J. B. (2002). Changing Trends in the Brazilian Medical Education. Doctoral Thesis, National School of Public Health, Osvaldo Cruz Foundation.

Landsberg, G. A. P. et al. (2012). Analysis of Demand for Family Medical Care in Brazil Using the International Classification of Primary Care. Ciência \& Saúde Coletiva, 17, 3025-3036.

Macdowell, M., Glasser, M., \& Hunsaker, M. (2013). A Decade of Rural Physician Workforce Outcomes for the Rockford Rural Medical Education (RMED) Program, University of Illinois. Acadamic Medicine, 88, 1941-1947. http://dx.doi.org/10.1097/acm.0000000000000031

Magnago, R. F., Moreira, D. S., Cunha, L., \& Sakae, T. M. (2009). Profiling the Users of the Family Health Clinic in Humaitá Neighborhood, Tubarão-SC. Associação Catarinense de Medicina, 8, 12-20.

Mendoza-Sassi, R., \& Béria, J. U. (2001). Health Services Utilization: A Systematic Review of Related Factors. Cadernos de Saúde Pública, 17, 819-832. http://dx.doi.org/10.1590/S0102-311X2001000400016

Merhy, E. E. (2005). Health: The Mapping of Living Labor (2nd ed.). São Paulo: Hucitec.

Ministry of Education (2004). Federal University of Santa Maria/Board of Education, Research and Extension, Political and Educational Project, Opinion 02/04, 2004.

Ministry of Education (2004). Federal University of Santa Maria-Medicine Program/Course Content.

Moraes, M. et al. (2007). Demand study in a Primary Health Care Unit in Pelotas. Revista de Saúde Universidade Católica de Pelotas, 1, 39-44.

Ottmani, S. E., Scherpbier, R., Chaulet, P., Pio, A., Van Beneden, C., \& Raviglione, M. (2004). Respiratory Care in Primary Care Services-A Survey in 9 Countries. WHO/HTM/TB/2004.333, Geneva, Switzerland: WHO.

Pereira, M, G. (2009). Epidemiology; Theory and Practice. Rio de Janeiro: Guanabara Koogan.

Piccini, R. X., \& Victora, C. G. (1994). Systemic Arterial Hypertension in an Urban Area of Southern Brazil: Prevalence and Risk Factors. Revista de Saúde Pública, 28, 261-267.

Pimentel, I. R. S. et al. (2011). Description of Demand in a Family Health Unit. Revista Brasileira de Medicina de Família e Comunidade, 6, 175-181.

Radaeli, S. M., Takeda, S. M. P., Gimeno, L. I. D., Wagner, M. B., Kanter, F. J., Mello, V. M. et al. (1990). The Demand for Community Health Services in the Metropolitan Periphery Area. Revista de Saúde Pública, 24, 232-240.

Rondet, C., Cornet, P., Kaoutar, B., Lebas, J., \& Chauvin, P. (2013). Depression Prevalence and Primary Care among Vulnerable Patients at a Free Outpatient Clinic in Paris, France, in 2010: Results of a Cross-Sectional Survey. BMC Family Practice, 14, 151. http://dx.doi.org/10.1186/1471-2296-14-151

Ruiz, D. G., Farenzena, G. J., \& Haeffner, L. S. B. (2010). Regional Internship and Medical Training: Perceptions among the First Medical School Class after a Curricular Reform. Revista Brasileira de Educação Médica, 34, 21-27. http://dx.doi.org/10.1590/S0100-55022010000100004

Ruiz, T., Valenza, P. D., Euclydes, M. P., Oliveira, M. C. F., \& Garcia, M. L. F. (1985). The Rural Internship of the Graduation Course in Nutrition of the Federal University of Viçosa (Brazil). Revista de Saúde Pública, 19, 566-569. http://dx.doi.org/10.1590/S0034-89101985000600008

Sala, A., Nemes, M. I. B., \& Cohen, D. D. (1998). Methodology for the Assessment of Activities in Primary Health Care. Cadernos de Saúde Pública, 14, 741-751. http://dx.doi.org/10.1590/S0102-311X1998000400016

Santa-Rosa, T. T. A., Vargas, A. M. D., \& Ferreira, E. F. (2007). Rural Internship and the Education of Dentistry Students at UFMG. Interface-Comunicação, Saúde, Educação, 11, 451-466. http://dx.doi.org/10.1590/S1414-32832007000300005

Smith, S. E., Tallentire, V. R., Cameron, H., \& Wood, S. M. (2013). The Effects of Contributing to Patient Care on Medical Students Workplace Learning. Medical Education, 47, 1184-1196. http://dx.doi.org/10.1111/medu.12217

Souza Campos, G. W. (2007). The Role Played by the Primary Health Care Network in Medical Education. Diretrizes. Cadernos ABEM, 3. 
Starfield, B. (1994). Is Primary-Care Essential? The Lancet, 344, 1129-1133. http://dx.doi.org/10.1016/S0140-6736(94)90634-3

Starfield, B. (2002). Primary Care: The Balance in the Need of Health, Services and Technologies. Brasília: UNESCO, Ministry of Health.

Streit, S. D., Maciel, T. D., \& Zanolli, M. B. (2009). Contribution to the Education of Doctors According to the Needs of Society: the Interaction with the Education, Service and Society Articulation Policies Established by the Ministry of Health. Cadernos da ABEM, 5.

Tomasi, E. et al. (2011). Characteristics of Primary Healthcare Service Use in the Southern and Northeastern Regions of Brazil: Differences by Care Model. Ciência \& Saúde Coletiva, 16, 4395-4404.

Travassos, C., Viacava, F., Pinheiro, R., \& Brito, A. (2002). Utilization of Health Care Services in Brazil: Gender, Family Characteristics and Social Status. Revista Panamericana de Salud Pública, 11, 365-373. http://dx.doi.org/10.1590/S1020-49892002000500011

World Health Organization (2003). Innovative Care for Chronic Conditions: Building Blocks for Action: Global Report. Brasília: World Health Organization.

\section{Submit or recommend next manuscript to SCIRP and we will provide best service for you:}

Accepting pre-submission inquiries through Email, Facebook, LinkedIn, Twitter, etc. A wide selection of journals (inclusive of 9 subjects, more than 200 journals)

Providing 24-hour high-quality service

User-friendly online submission system

Fair and swift peer-review system

Efficient typesetting and proofreading procedure

Display of the result of downloads and visits, as well as the number of cited articles

Maximum dissemination of your research work

Submit your manuscript at: http://papersubmission.scirp.org/ 